\title{
Disruptive effects of prior information on tachistoscopic recognition
}

\author{
W. TRAMMELL NEILL and JOHN R. WALLING \\ University of South Florida, Tampa, Florida 33620
}

\begin{abstract}
Smith, Haviland, Reder, Brownell, and Adams (1976) found tachistoscopic letter recognition to be disrupted by advance information about possible letter alternatives. An association of "before-disruption" with a bias to respond "same" in same-different judgment led Smith et al. to conclude that incidental mask features corresponding to a precued letter were erroneously incorporated into the target letter decision. Experiments 1 and 2 in the present study failed to replicate the before-disruption effect under conditions similar to those of Smith et al., although precuing produced a strong bias to respond "same." Similarity between "same" and "different" alternatives was manipulated in Experiment 3 by selecting letter pairs differing in one critical feature (P-R, O-Q, C-G, F-E) for one group of subjects, and re-pairing the same letters (P-G, O-E, C-R, F-Q) for another group. Contrary to Smith et al., precuing interacted significantly with pair similarity, such that before-disruption occurred only with similar alternatives. In contrast, precuing produced equivalent "same-bias" in both groups. The dependence of before-disruption on pair similarity was extended to two-alternative forced-choice recognition in Experiment 4. Together with inconsistencies in the Smith et al. data and more detailed analysis of present recognition errors, the results suggest (1) the before-disruption and same-bias effects of precuing are mediated by separate mechanisms, and (2) before-disruption reflects loss of target letter information rather than direct incorporation of extraneous mask features.
\end{abstract}

Advance information about an upcoming stimulus, decision, or response has been found to facilitate performance in many different tasks (see, for example, Haber, 1966; LaBerge, Peterson, \& Norden, 1977; Posner \& Snyder, 1975). Several studies have found that forcedchoice recognition of a brief tachistoscopic target is improved if the relevant stimulus alternatives are presented to the subject prior to presentation of the target (e.g., Egeth \& Smith, 1967; Gummerman, 1971; Long, Reid, \& Henneman, 1960). A striking counterexample to these results, first noted by Reicher (1969), has been extensively explored by Smith, Haviland, Reder, Brownell, and Adams (1976). In a series of experiments requiring either forced-choice recognition (two alternatives) or "same-different" matching (one alternative) of single-letter targets, performance was actually depressed by foreknowledge of the alternative(s). Smith et al. attributed this "before-disruption" effect to the incidental use of a masking pattern to limit the visibility of the target. In particular, they hypothesized that precuing

We are indebted to Brenda Buttram, Maria Blanco-Cruz, John Desmond, Maggie Duchaine, Eva Fernandez, Neil Folsom, Mark Fountain, Hadley Garbart, Ellen Hanis, Diane Hungerford, Phil Jacob, April Kassover, Ed McGrath, Mark Mincey, Steve Pena, Jan Posey, Ann Rosati, Lee Solomon, Mike Stern, Tom Studer, Ginger Tyndall, and Bill Valle for assistance in data collection, to Steve Hekkanen for technical assistance, and to Dewey Rundus for helpful comments. Requests for reprints should be sent to W. Trammell Neill, Department of Psychology, University of South Florida, Tampa, Florida 33620. led subjects to look for particular features of a letter alternative. If these features happened to be present in the mask, subjects might erroneously include these mask features in the letter decision, in effect "seeing" that which was sought regardless of the true target identity. In the same-different task, sought-for features would be those of the single presented alternative, making a "same" response very likely. Smith et al. (1976, Experiment 2) confirmed the coexistence of "same-bias" and before-disruption when subjects received the comparison stimulus before the tachistoscopic target.

Smith et al. (1976) tested their account of beforedisruption by manipulating masking conditions in three experiments (Experiments 3, 4, and 5). In their Experiments 3 and 4 , they compared precuing effects in conditions with and without pattern masks. Overall target visibility was roughly equated for the two viewing conditions by considerably reducing illumination of the target in the no-mask condition. In both forced-choice recognition (Experiment 3) and same-different matching (Experiment 4), before-disruption occurred only with mask present. In the no-mask conditions, presentation of the alternative(s) before the target facilitated, rather than disrupted, performance. However, while the results directly confirm the importance of masking conditions for before-disruption, the results of their Experiment 4 were not wholly consistent with the mechanism proposed by Smith et al. As shown in Table 1, the bias to respond "same," manifested in better performance on same trials than on different trials, was actually stronger in the 
Table 1

Proportions of Correct "Same" and "Different" Responses for the Before and After Conditions (Smith et al., 1976, Experiment 4)

\begin{tabular}{lccccc}
\hline & \multicolumn{2}{c}{ Mask } & & \multicolumn{2}{c}{ No Mask } \\
\cline { 2 - 3 } Response & Before & After & Before & After \\
\hline Same & .85 & .75 & .90 & .62 \\
Different & .74 & .91 & .67 & .85 \\
Average & .80 & .83 & .78 & .74 \\
\hline
\end{tabular}

Table 2

Proportions of Correct "Same" and "Different" Responses for the Before and After Conditions as a Function of Mask-Alternative Similarity (Adapted from Smith et al., 1976, Experiment 5)

\begin{tabular}{lcccc}
\hline & \multicolumn{2}{c}{$\begin{array}{c}\text { Similar Mask and } \\
\text { Alternative }\end{array}$} & \multicolumn{2}{c}{$\begin{array}{c}\text { Dissimilar Mask and } \\
\text { Alternative }\end{array}$} \\
\cline { 2 - 5 } Response & Before & After & Before & After \\
\hline Same & .80 & .61 & .76 & .71 \\
Different & .65 & .87 & .76 & .92 \\
Average & .73 & .74 & .76 & .82 \\
\hline
\end{tabular}

precued before condition relative to the unprecued after condition without the mask than with the mask present. Since Smith et al. attributed before-disruption and same-bias to the same mechanism, the same-bias effect of precuing should have been attenuated in the no-mask condition.

Smith et al. (1976) acknowledged the mixed support for their masking hypothesis and proceeded to offer in their Experiment 5 "an even more demanding test" (p. 158). It follows from their hypothesis that beforedisruption and the concomitant same-bias are more likely when features of the mask are more similar to features of the comparison stimulus. For example, angular mask features are more likely than are curvilinear features to be misperceived as the alternative "A." Accordingly, Smith et al. employed two sets of letter alternatives, one set containing angular letters and the other set containing curvilinear letters. Similarly, two sets of masks were constructed, consisting of either angular or curvilinear features. As predicted, precuing caused a stronger same-bias when the mask and alternative features were similar than when they were dissimilar. However, Smith et al. avoid discussion of the precuing effects on overall performance and omit averages combined over same and different trials, which are reconstructed in Table 2. A convincing before-disruption effect is seen to have occurred only when mask and alternative features were dissimilar. When mask and alternative were similar, there was little, if any, effect of presenting the alternative before the target relative to presenting it only afterward. Thus, the Smith et al. hypothesis is directly contradicted by the beforedisruption effects in their Experiment 5, just as it was contradicted by the same-bias effects in their Experiment 4 .

As a whole, the Smith et al. (1976) data suggest that the before-disruption and same-bias effects of precuing are somewhat independent, although Smith et al. attribute the effects to the same mechanism. Since the existence of before-disruption seems to contradict fundamental assumptions of facilitation by advance information (e.g., LaBerge et al., 1977; Posner \& Snyder, 1975; Smith \& Spoehr, 1974), it is difficult to overemphasize the importance of achieving a more adequate explanation of this very counterintuitive phenomenon.

\section{EXPERIMENT 1}

Experiment 1 attempted to replicate the beforedisruption and same-bias effects of precuing found by Smith et al. (1976) in the same-different task, with the addition of a third condition to examine one alternative explanation of the effects. In the precued "before" condition, Smith et al. showed subjects the comparison stimuli both before and after the tachistoscopic target. In the unprecued "after" condition, subjects viewed a blank card prior to the target and saw the comparison stimulus only after the target. As a result, precuing was confounded with number of presentations of the comparison stimulus. It is conceivable that subjects performed the matching task in both conditions by searching short-term memory for a match to the final comparison stimulus. In the precued before condition, a spurious match might occur with the memory for the initial presentation of the comparison stimulus. Such a failure to discriminate between the memories of the target and the comparison stimulus would not only reduce performance (before-disruption) but would also produce a bias to respond "same." The present experiment added a true "before" condition, in which subjects saw the comparison stimulus only before the target and viewed a blank card after the target. The original "before" condition employed by Smith et al. will herein be referred to as the "combined" condition, as it really combines before and after presentations of the comparison stimulus. If the matching task requires a search through short-term memory, the new before condition should force subjects to make a decision immediately after the target presentation, rather than to wait for a second presentation of the comparison stimulus. Thus, the "memory confusion" hypothesis predicts that performance would be distupted only in the combined condition and not in the new before condition, relative to the unprecued after condition. On the other hand, if precuing really disrupts perception of the target stimulus, the before-disruption and same-bias effects should be apparent in both the before and the combined conditions.

\section{Method}

Subjects. Twenty-six University of South Florida undergraduates each participated in an individual 1-h session for course credit. Two subjects were replacements for two subjects eliminated due to procedural errors, to compose a subject sample of 24.

Stimuli and Apparatus. The stimuli consisted of all 26 capital letters of the English alphabet, in Prestige Elite 10 type on white cards. Stimuli were presented in a Polymetric V-0959 two- 
channel tachistoscope with auxiliary Hunter Model 115 and 111-C timers. A stimulus letter subtended a visual angle of approximately $0 \mathrm{deg} 30 \mathrm{~min}$ vertically and $0 \mathrm{deg} 20 \mathrm{~min}$ to 0 deg 25 min horizontally.

Procedure. The procedures for the after and combined conditions were similar in most respects to the after and before conditions, respectively, employed by Smith et al. (1976, Experiment 2). In an after condition trial, the subject first viewed a blank white card, hand-held by the experimenter. After acknowledging that the card had been seen, the subject was allowed to look into the tachistoscope. The experimenter then announced "ready" and initiated an audible timer. At $1 \mathrm{sec}$ after initiation, the target letter was presented for a predetermined duration, immediately followed by a masking pattern of superimposed Xs and Os lasting approximately $500 \mathrm{msec}$. The subject then looked at another hand-held card on which a letter alternative was printed. The subject was required to verbally respond "same" if he or she believed the target and the comparison stimulus to be identical and to respond "different" if he or she believed them to be different. The experimenter recorded the response, and, if appropriate, began the next trial. Procedure in the combined condition was identical, except that the subject was also shown the comparison stimulus instead of a blank card before looking in the tachistoscope. In the before condition, the subject was shown the comparison stimulus only before looking in the tachistoscope, and he or she saw a blank card after the tachistoscopic presentation. The subject was required in all conditions to withhold overt responding until the final presentation of either a blank or a printed card. Use of blank cards in the after and before conditions insured equivalent procedural time courses and exposure effects across all three conditions.

The choice of "different" alternatives was preexperimentally determined by pairing each letter with another letter of the alphabet, resulting in 13 stimulus pairs. The pairs were arbitrarily chosen by the experimenters to be featurally similar (e.g., P-R, F-E), but use of all 26 letters necessitated some compromises of less similarity (e.g., A-H, S-Z). The importance of pair similarity will be discussed in later experiments.

Conditions were run in separate blocks, with order counterbalanced across subjects by assigning four subjects to each of the six possible orders of three conditions. Each block employed all 26 letters as alternatives, yielding 26 trials per block. Each subject participated in six blocks, the first three of which were designated as practice, with the order of conditions repeated again for the final three experimental blocks. Each block employed a different order of alternatives randomly predetermined at the beginning of the experiment, which remained constant over subjects but was counterbalanced across conditions by the order assignments. "Same" and "different" trials were randomly determined for each subject with the constraint of 13 "same" and 13 "different" trials within each block.

The duration of the target letter was initially set to $70 \mathrm{msec}$ for the practice blocks. In an attempt to minimize ceiling effects on performance, exposure duration was shortened by $10 \mathrm{msec}$ for each practice block in which two or fewer errors were made. The resulting final exposure duration was held constant over the experimental blocks. Specific experimental block durations were $70 \mathrm{msec}$ for 10 subjects, $60 \mathrm{msec}$ for 12 subjects, $50 \mathrm{msec}$ for 1 subject, and $40 \mathrm{msec}$ for 1 subject.

\section{Results and Discussion}

An analysis of variance of the data shown in Table 3 revealed a significant main effect of response ("same" vs. "different") $[F(1,23)=17.47, p<.01]$ and a significant interaction of response with conditions $[F(2,46)=$ 13.16, $\mathrm{p}<.01]$. Unlike the comparable study by Smith et al. (1976, Experiment 2), there was no main effect of conditions $[F(2,46)<1]$. The present experi-
Table 3

Proportions of Correct "Same" and "Different" Responses for the Before, Combined, and After Conditions (Experiment 1)

\begin{tabular}{lccc} 
& \multicolumn{3}{c}{ Condition } \\
\cline { 2 - 4 } Response & Before & Combined & After \\
\hline Same & .87 & $.87(.93)$ & $.76(.84)$ \\
Different & .61 & $.63(.61)$ & $.72(.88)$ \\
Average & .74 & $.75(.77)$ & $.74(.86)$ \\
\hline
\end{tabular}

Note-The data from Smith et al. (1976, Experiment 2) are presented in parentheses for comparison. The present "com. bined" condition was referred to as the "before" condition in their study.

ment replicated the strong same-bias effect of precuing found by Smith et al. manifested in the relatively large same-different asymmetry for both the before and the combined conditions. However, there was no disruption of overall performance relative to the after condition. Insofar as the before and combined conditions are similar in same-bias and both differ from the after condition in that respect, the data do suggest that precuing has some effect on performance that does not depend on the second presentation of the comparison stimulus. As such, the data do not support the "memory confusion" hypothesis suggested earlier, although any conclusions must be tempered by the lack of an overall disruption effect.

A signal detection theory analysis of the data (cf. Egan, 1975; Green \& Swets, 1966) supported the conclusion that precuing resulted in a response bias but no disruption of overall performance. The measure of sensitivity independent of bias, $\mathrm{d}^{\prime}$, was 1.62 for the before condition, 1.69 for the combined condition, and 1.58 for the after condition, which did not differ significantly. ${ }^{1}$ The measure of response bias, $\beta$, was also calculated, yielding values of $.46, .43$, and 1.21 , respectively. ${ }^{2}$ Both the before and the combined conditions differed significantly from the after condition $[\mathrm{t}(23)=2.74, \mathrm{p}<.02$, and $\mathrm{t}(23)=2.48, \quad \mathrm{p}<.05$, respectively]. (All reported $t$ tests are two-tailed.) The before and combined conditions did not differ significantly from each other.

The failure to obtain a main effect of conditions in the analysis of variance of the recognition percentages is not likely to reflect a lack of experimental sensitivity, since the interaction with response, attributed by Smith et al. (1976) to the same mechanism, was so clearly obtained. However, it should be noted that the sampling procedures of the present experiment differed somewhat from the comparable experiment by Smith et al. (1976, Experiment 2). The experimental data analyzed by Smith et al. consisted of 52 trials (two blocks) per condition for each of 8 subjects, whereas the present experimental data consisted of 26 trials (one block) per condition for each of 24 subjects. In addition, subjects in Smith et al's. Experiment 2 received much more practice prior to collection of the experimental data, two complete sessions prior to their third, critical 
session. Thus, while the present experiment collected $50 \%$ more responses per condition than the comparable Smith et al. experiment, each subject in the latter study received considerably more exposure to the task. It is conceivable that the before-disnuption effect emerges with the development of strategies requiring practice in the experimental conditions (although the same-bias effect may not). Experiment 2 was carried out over five sessions to test this explanation of the failure to find a before-disruption effect in Experiment 1.

\section{EXPERIMENT 2}

\section{Method}

Subjects. Six University of South Florida undergraduates each participated in five individual 1 -h sessions for course credit.

Stimuli and Apparatus. Stimuli and apparatus were identical to those in Experiment 1.

Procedure. Each subject participated in five sessions, six experimental blocks per session. Each subject was assigned to a different order of the three conditions, before, combined, and after. The order assigned to the first three blocks for a subject was repeated for the second half of the session and for each session thereafter. To compensate for anticipated improvements in performance over sessions, the duration of the target stimulus was set to $70 \mathrm{msec}$ for the first session, $60 \mathrm{msec}$ for the second, $50 \mathrm{msec}$ for the third, $40 \mathrm{msec}$ for the fourth, and $30 \mathrm{msec}$ for the fifth. Stimulus duration was not changed between conditions within a session.

All other aspects of procedure were identical to those of Experiment 1.

\section{Results and Discussion}

An analysis of variance was performed on the data from Experiment 2, with factors of condition, response, session, and replication (first half or second half within session). A significant main effect of replication $[F(1,5)$ $=9.73, p<.05]$ reflected an overall within-session practice effect that did not interact with any other factors and will not be discussed further. The data shown in Table 4 are averaged over session halves. A significant main effect of session $[F(4,20)=3.14$, $\mathrm{p}<.05]$ reflects practice effects over sessions in combination with changes in stimulus duration and is also of little theoretical interest. More important results were a significant main effect of response $[F(1,5)=$ $26.82, p<.01]$ and an interaction of response with condition $[F(2,10)=7.45, p<.02]$. No other effects were significant at conventional levels, although a triple interaction of Response by Condition by Session approached significance $[F(8,40)=1.93, p<.10]$. Notably absent were a main effect of condition and interaction of condition with session $(F<1$ for both effects).

The basic pattern of results was markedly similar to Experiment 1, despite the extensive exposure of each subject to the task. As shown in Table 4, a strong bias to response "same" was present throughout for the precued before and combined conditions. The after condition showed a weaker bias toward "same" responding in
Table 4

Proportions of Correct "Same" and "Different" Responses for the Before, Combined, and After Conditions Over Five Sessions (Experiment 2)

\begin{tabular}{lcccccc}
\hline & \multicolumn{6}{c}{ Session } \\
\cline { 2 - 6 } Response & 1 & 2 & 3 & 4 & 5 & All \\
\hline Same & .87 & .80 & .83 & .74 & .75 & .80 \\
Different & .72 & .62 & .61 & .52 & .53 & .60 \\
Average & .80 & .71 & .72 & .63 & .64 & .70 \\
& \multicolumn{7}{c}{ Combined Condition } \\
Same & .90 & .81 & .82 & .75 & .75 & .81 \\
Different & .71 & .62 & .67 & .51 & .59 & .62 \\
Average & .80 & .72 & .75 & .63 & .67 & .71 \\
& \multicolumn{7}{c}{ After Condition } \\
Same & .81 & .72 & .72 & .68 & .66 & .72 \\
Different & .73 & .80 & .74 & .72 & .72 & .74 \\
Average & .77 & .76 & .73 & .70 & .69 & .73 \\
\hline
\end{tabular}

the first session that reversed in later sessions toward "different" responding, contributing to the marginal triple interaction noted above.

The conclusions drawn from the recognition percentages were again confirmed by analyses of variance for the signal detection theory measures of sensitivity $\left(d^{\prime}\right)$ and response bias $(\beta)$, combining "same" and "different" responses (as required for SDT analysis) and collapsing over session halves. For $\mathrm{d}^{\prime}$, the only signifi cant effect was for session $[F(4,20)=3.41, p<.05]$, with no effect of condition $(F<1)$ and no interaction of condition with session $(F<1)$. The mean $d^{\prime}$ scores were 1.25 for the before condition, 1.50 for combined, and 1.56 for after, with no significant differences between any pair of conditions by $t$ test. On the other hand, the analysis of variance for $\beta$ revealed significant effects of condition $[F(2,10)=12.13, p<.01]$ and session $[F(4,20)=3.63, p<.05]$. The interaction of these two factors was not significant $(F<1)$. Averaged over sessions, the mean $\beta$ values were .65 for the before condition, .57 for combined, and .88 for after. Both the before and combined conditions had significantly smaller $\beta$ values than the after condition (reflecting greater same-bias) $[\mathrm{t}(5)=3.11, \mathrm{p}<.05$, and $\mathrm{t}(5)=3.52$, $\mathrm{p}<.02$, respectively], but they did not differ from each other.

Both Experiment 1 and Experiment 2 failed to replicate the before-disruption effect described by Smith et al. (1976), yet they easily demonstrated the predicted same-bias in the precuing conditions. The simplest interpretation of these results is that beforedisruption and the same-bias effect reflect separate causes, contrary to the Smith et al. attribution of both to the same mechanism. However, there are at least two alternative interpretations. First, as suggested by Smith et al., precuing may cause both facilitatory and disruptive effects. It is therefore possible that the mechanism proposed by Smith et al. caused both before-disruption 
and same-bias in the present precuing conditions, but some facilitatory effect of precuing (such as reduced stimulus uncertainty) compensated for the disruptive effect, leaving only the response bias overtly mani. fested in the data. Second, there may be several possible causes of response bias, only one of which is associated with the mechanism of before-disruption. The present experiments may have failed to produce the necessary conditions for before-disruption and its associated response bias, but at the same time they could have introduced some other irrelevant source of response bias. This would certainly question the robustness of the before-disruption effect, but it would obviously not reject the mechanism proposed by Smith et al. On the other hand, these alternative explanations would be excluded if conditions were found that produced a before-disruption effect without increasing same-bias.

\section{EXPERIMENT 3}

Smith et al. (1976, p. 154) concluded from infor. mally described data that "before-disruption does not seem to depend on the similarity of the alternatives." However, data from an experiment by Neill (Note 1) suggested to us that a difference in average similarity of "same" and "different" alternatives might account for the failure to replicate the before-disruption effect found by Smith et al. Accordingly, intrapair similarity was deliberately manipulated in Experiment 3 by selecting for one group of subjects four pairs of alternatives (O-Q, F-E, C-G, P-R) such that letters within a pair were maximally similar, differing in only one critical feature ("like" condition). For another group, the same letters were re-paired (O-E, F-Q, C-R, P-G) such that letters within a pair were very dissimilar ("unlike" condition).

The choice of letter pairs in the "like" condition provides a further test of the Smith et al. (1976) hypothesis: Importation of mask features into the letter decision should make a target such as $F$ misperceived as $\mathrm{E}$ more readily than $\mathrm{E}$ should be misperceived as $\mathrm{F}$. In other words, more errors should occur on precued trials in which the target is distinguished by the absence of the critical feature ("unmarked" targets) than on precued trials in which the target contains the critical feature ("marked" targets).

\section{Method}

Subjects. Nineteen University of South Florida undergraduates each participated in an individual 1-h session for course credit. Three subjects replaced 3 subjects discarded because of procedural errors, to compose a sample of 16 subjects. None had participated in the previous experiments.

Stimuli and Apparatus. Stimuli were drawn from the set of uppercase letters C, G, P, R, O, Q, F, and E. All other aspects of stimuli and apparatus were identical to those of previous experiments.

Procedure. Each subject participated in two practice blocks of 24 trials with a target duration of $160 \mathrm{msec}$, followed by six experimental blocks of 24 trials with a target duration of $60 \mathrm{msec}$. Before condition blocks were alternated with after condition blocks, beginning with the before condition for half the subjects and with the after condition for the other half.

Eight subjects were assigned to the "like" condition, in which the "different" alternative was visually similar to the "same" alternative, with letter pairings C-G, F-E, O-Q, and P-R. Thus, for example, a "different" target stimulus for the alternative $C$ would be $G$, and vice versa. The other eight subjects were assigned to the "unlike" condition, in which the "different" alternative was visually dissimilar to the "same" alternative, with letter pairings $C-R, F-Q, O-E$, and $P-G$.

"Same" and "different" trials and choice of alternatives and targets were randomly predetermined, with the constraint that each letter be used equally of ten as a comparison stimulus and that each letter appear equally often as a "same" and as a "different" target stimulus.

All other aspects of procedure were identical to those of Experiments 1 and 2 .

\section{Results and Discussion}

An analysis of variance of the data shown in Table 5 yielded significant interactions of precuing with response $\{F(1,14)=10.16, p<.01\}$ and of precuing with pair similarity $[F(1,14)=9.78, p<.01]$. No main effects or other interactions were significant. As in previous experiments, precuing resulted in a strong bias to respond "same" in the before condition. This same-bias effect occurred for both similar and dissimilar pairings; there was no hint of a Precuing by Response by Similarity triple interaction $(F<1)$. On the other hand, a before-disruption effect was present for all eight subjects in the like condition, whereas a nonsignificant trend toward before-facilitation was present in the unlike condition. The conclusion that precuing caused a samebias regardless of pair similarity but caused beforedisruption only for similar pairs is supported by the signal detection theory measures shown in Table 6. An analysis of variance of $\mathrm{d}^{\prime}$ revealed a significant interaction of precuing with pair similarity $[\mathrm{F}(1,14)=7.67$, $p<.02$ ], but no significant main effect of either variable. In contrast, the response bias measure $\beta$ yielded only a significant main effect of precuing $[F(1,14)=$ $4.63, p<05$ ]. The reduction in $\beta$ (i.e., increase in same-bias) for the before condition was in fact slightly larger for dissimilar pairs.

The results strongly support the conclusions that before-disruption depends on similarity between alternatives and that before-disruption and same-bias effects of precuing are mediated by separate mechanisms. Further evidence against the Smith et al. (1976) explanation of before-disruption was found in the analysis of particular letter errors in the like condition: Whereas

Table 5

Proportions of Correct "Same" and "Different" Responses for the Before and After Conditions as a Function of Alternative-Pair Similarity (Experiment 3)

\begin{tabular}{lccccc} 
& \multicolumn{2}{c}{ Similar Pairs } & & \multicolumn{2}{c}{ Dissimilar Pairs } \\
Response & Before & After & Before & After \\
\hline Same & .72 & .75 & .82 & .76 \\
Different & .61 & .77 & .75 & .77 \\
Average & .67 & .76 & .79 & .77 \\
\hline
\end{tabular}


Table 6

Signal Detection Theory Measures of Sensitivity ( $d^{\prime}$ ) and Response Bias $(\beta)$ for the Before and After Conditions as a Function of Alternative-Pair Similarity (Experiment 3)

\begin{tabular}{lccccc} 
& \multicolumn{2}{c}{ Similar Pairs } & & \multicolumn{2}{c}{ Dissimilar Pairs } \\
\cline { 2 - 3 } \cline { 5 - 6 } Condition & $\mathrm{d}^{\prime}$ & $\beta$ & & $\mathrm{d}^{\prime}$ & $\beta$ \\
\hline Before & .89 & .89 & & 1.79 & .99 \\
After & 1.55 & .98 & & 1.62 & 1.13 \\
\hline
\end{tabular}

the Smith et al. account would predict a majority of errors to occur on unmarked targets $(\mathrm{O}, \mathrm{F}, \mathrm{P}, \mathrm{C})$, in fact, slightly less than half $(47 \%)$ of the errors in the like-before condition involved unmarked targets. This proportion also did not differ from the like-after condition (also 47\%). Thus, before-disruption seems better described as a loss of information about the target stimulus than as the erroneous inclusion of mask features in the letter decision.

Insofar as the like and unlike alternative pairings differed only in physical similarity, it seems likely that the pairings determined a processing and/or decision strategy reflecting that similarity. We surmise that like pairings induced subjects to test for the presence or absence of the distinguishing feature, whereas unlike pairings induced subjects to rely on whole-letter recognition. The question remains whether the obtained similarity effect depended on similarity per se or only on the subject's ability to reconstruct the identity of a "different" target as a prerequisite for generating a feature-specific test. For example, it may be easier when precued with $\mathrm{C}$ to remember that the target must be $\mathrm{C}$ or $\mathrm{G}$ (like condition) than to remember that the target must be $\mathrm{C}$ or $\mathrm{R}$ (unlike condition). If pair similarity allows the subject only to anticipate the "different" target, the similarity effect on before-disruption should be eliminated in a forced-choice task in which both alternatives are presented simultaneously.

\section{EXPERIMENT 4}

\section{Method}

Subjects. Twenty-six University of South Florida undergraduates each participated in an individual $1-\mathrm{h}$ session in exchange for course credit. Six subjects replaced 3 subjects discarded because of procedural errors and 3 others discarded because of failure to achieve greater than chance performance in the practice blocks, to compose a final sample of 20 subjects. None had participated in the previous experiments.

Stimuli and Apparatus. Stimuli and apparatus were identical to Experiment 3.

Procedure. Procedure was identical to Experiment 3, except that subjects were shown two alternatives side by side either before or after the tachistoscopic target presentation and, consequently, were instructed to name the letter alternative believed to match the target. Ten subjects were assigned to the like condition and 10 to the unlike condition.

\section{Results and Discussion}

An analysis of variance of the data shown in Table 7 revealed a significant main effect of precuing $[F(1,18)=$
$7.69, \mathrm{p}<.02$ ] in the direction of an overall beforedisruption, as well as a marginally significant interaction of precuing with pair similarity $[F(1,18)=3.23, p<.10]$. The reliability of the interaction is supported by the fact that all 10 subjects in the like condition were consistent with before-disruption, whereas subjects were evenly split in the unlike condition. The difference between before and after conditions for subjects in the like condition (.68 vs. .77$)$ was highly significant $[\mathrm{t}(9)=5.25$, $p<.001]$, whereas the difference for subjects in the unlike condition (.77 vs. .78) was negligible $[\mathrm{t}(9)=.51$, n.s.]. The strong before-disruption effect in the like condition in conjunction with the negligible effect in the unlike condition forcibly argues that before-disruption does depend on similarity of the alternatives, even when subjects are fully informed of both possible targets.

Once again, analysis of specific letter errors failed to support the Smith et al. (1976) account of beforedisruption. Slightly over half the errors in the likebefore condition occurred on unmarked targets (.56), which did not differ significantly either from the likeafter condition (.44) $[\mathrm{t}(9)=1.28, \mathrm{n} . \mathrm{s}$.] or from chance (.50) $[\mathrm{t}(9)=.93$, n.s. $]$.

A particularly surprising result in both Experiments 3 and 4 was that overall performance for subjects in the like condition did not differ significantly from subjects in the unlike condition. In the after presentation conditions, the like vs. unlike differences were particularly negligible: .76 vs. .77 in Experiment 3 and .77 vs. .78 in Experiment 4. Since subjects could not anticipate specific stimuli in the after conditions, immediate processing of the target would be unlikely to be influenced by the alternative pairings. However, the subsequent decision should have been easier with unlike alternatives than with like alternatives if the subjects retained only partial information about the target. For example, since $\mathrm{F}$ is more confusable with $\mathrm{E}$ than with $\mathrm{Q}$, the target $\mathrm{F}$ would more likely be misperceived as E. On such trials, the subject would necessarily make an incorrect choice in the like condition, in which $E$ is a valid alternative. In the unlike condition, however, the subject faced with $F$ or $Q$ or both as alternatives should easily reject $Q$ and reconstruct $\mathrm{F}$ as the correct choice. Even if the subject failed to employ a sophisticated guessing strategy for miscategorized targets, chance guessing in the unlike condition should produce more correct responses than in the like condition, in which misperception would systematically lead to the incorrect choice. However,

Table 7

Proportions of Correct Forced-Choice Responses in the Before and After Conditions as a Function of Alternative-Pair Similarity (Experiment 4)

\begin{tabular}{ccc}
\hline & \multicolumn{2}{c}{ Pair Similarity } \\
\cline { 2 - 3 } Condition & Similar & Dissimilar \\
\hline Before & .68 & .77 \\
After & .77 & .78 \\
\hline
\end{tabular}


there appears to be little, if any, such effect of similarity between alternatives. In comparison with the dramatic interaction of similarity with precuing, this suggests that the importance of letter misidentification due to confusability per se (e.g., Townsend, 1971) is minor relative to the effects of processing and/or decision strategies employed in letter recognition. Thompson and Massaro (1973) offer a somewhat similar conclusion.

\section{GENERAL DISCUSSION}

The results of the foregoing experiments compel the conclusion that the before-disruption and same-bias effects of precuing are mediated by separate mechanisms, contrary to the conclusions of Smith et al. (1976). Experiments 3 and 4 found before-disruption to occur only when potential "same" and "different" targets were very similar (in this case, differing in only one critical feature). In contrast, the same-bias effect of precuing in Experiment 3 was not affected by alternativepair similarity. Reicher (1969) and Smith et al. found before-disruption with substantially larger sets of letters than the restricted set employed in Experiments 3 and 4. Thus, the lack of before-disruption in the presence of a strong same-bias in Experiments 1 and 2 may be best explained by insufficiently similar alternative pairings for before-disruption to be manifested.

Since the precued "before" conditions in Experiments 3 and 4 did not employ a second presentation of the comparison stimulus, before-disruption does not seem to reflect memory confusion due to multiple presentations of the comparison stimulus (hypothesized in Experiment 1). Thus, before-disruption does appear to be a genuine effect of precuing on the immediate processing of the target stimulus. When alternative pairs differed in only one critical feature, precuing may have induced subjects to look for that particular distinguishing feature. However, when paired alternatives were very dissimilar, or when subjects were not precued, it may have been difficult to test for a particular distinguishing feature and easier to rely on identification of the whole target pattern. At least under present conditions, the latter strategy appears to be more efficient.

The data of Smith et al. (1976, Experiments 3 and 4) do imply that before-disruption depends on the presence of a pattern mask (which was always used in the present experiments). However, the mechanism Smith et al. proposed does not adequately describe the present data. First of all, they proposed that the precued subject is set to look for features of the comparison stimulus, without reference to the alternatives with which it is paired. Consequently, they explicitly (Smith et al., 1976, p. 154) dismissed any importance of alternative pair similarity. However, minor modifications of their model could accommodate effects of alternative pairing on feature selection. More important failings concern the manner in which the mask is proposed to interfere with the feature-testing strategy. Inclusion of the mask feature into the letter decision would result in false positive identification, and Smith et al. explicitly hypothesized a direct relation between before-disruption and same-bias. However, the present results (and careful inspection of the Smith et al. data) show that beforedisruption can occur without increasing same-bias, and vice versa. In addition, the Smith et al. account predicts that precuing should produce errors specifically on trials on which the critical distinguishing feature is absent ("unmarked" targets), since importation of mask features should add, but not subtract, that feature. In fact, errors were roughly divided evenly between marked and unmarked targets, and precuing did not alter this proportion relative to the unprecued "after" condition. Before-disruption therefore seems to reflect more a loss of information about the letter rather than the direct inclusion of mask features into the letter decision.

Why should the hypothesized feature-testing strategy be less efficient than a whole-letter processing strategy, at least in the presence of a pattern mask? It seems paradoxical that focusing a subject's attention on the single distinguishing feature should result in the loss of critical information for letter recognition. One possibility is that the feature-testing strategy may be more easily disrupted by masking than is whole-letter processing because feature testing interacts with the mask within a common visual processing subsystem. Wholeletter processing, on the other hand, may rely on a separate subsystem involving either naming or a more "abstract" visual classification (cf. Posner, 1969, 1978), which may be less vulnerable to masking. Another explanation could be that recognition of a letter is somehow more than recognition of its individual features, just as recognition of a word appears to be somehow more than recognition of its individual letters (Reicher, 1969). The variety of explanations proposed for the controversial "word superiority effect" might also apply to a "letter superiority effect." Whole-letter processing may take advantage of information regarding relations between features, such as overall letter shape (e.g., Bouma, 1971), as well as the features themselves. Alternatively, whole-letter processing may make information available from more processing subsystems (again, possibly naming or abstract visual classification) than feature testing, in the same manner that has been proposed for the superiority of word recognition over letter recognition (e.g., Hawkins, Reicher, Rogers, \& Peterson, 1976; Mezrich, 1973). Whatever the source of "extra" information in whole-letter processing, it is worth noting that masking conditions have also been invoked as critical in the word superiority effect (McClelland, 1976).

The same-bias effect of precuing does not seem to be affected by the similarity of paired "same" and "different" stimuli. The results of Smith et al. (1976, Experiment 4) suggest that it also does not depend on the presence of a mask, since precuing caused an even greater same-bias under no-mask conditions. It seems likely that the effect reflects a change in decision criteria at a level of processing independent of that at which 
before-disruption occurs. In the "logogen" model of recognition proposed by Morton (1969), precuing may lower the criterion for accumulated sensory evidence required to activate the precued letter's name. Broadbent (1971) refers to a similar concept as "pigeonholing." While the probability of correctly detecting the precued letter would increase, the probability that a different target would be miscategorized as the precued letter would also increase. This criterion change would then result in an increased proportion of "same" responses but no direct change in real performance (reflected in the signal detection theory measures, $\beta$ and $\mathrm{d}^{\prime}$, respectively). In contrast, the processing strategy adopted by the subject may directly affect the quality or quantity of accumulated sensory evidence and, consequently, affect overall performance.

\section{REFERENCE NOTE}

1. Neill, W. T. Disruptive effects of prior information on tachistoscopic recognition? Paper presented at the meeting of the Southeastern Psychological Association, New Orleans, March 1979.

\section{REFERENCES}

Bouma, H. Visual recognition of isolated lower-case letters. Vision Research, 1971, 11, 459-474.

Broadbent, D. E. Decision and stress. New York: Academic Press, 1971.

EgAN, J. P. Signal detection theory and ROC analysis. New York: Academic Press, 1975.

Egeth, H. E., \& Smith, E. E. Perceptual selectivity in a visual recognition task. Journal of Experimental Psychology, 1967, 74, 534-549.

Green, D. M., \& Swets, J. A. Signal detection theory and psychophysics. New York: Wiley, 1966.

Gummerman, K. Selective perception and the number of alternatives. American Journal of Psychology, 1971, 84, 173-179.

Haber, R. N. Nature of the effect of set on perception. Psy. chological Review, 1966, 73, 335-351.

Hawkins, H. L., Reicher, G. M., Rogers, M., \& Peterson, L. Flexible coding in word recognition. Journal of Experimental Psychology: Human Perception and Performance, 1976, 2 , 380-385.

LaBerge, D., Peterson, R. J., \& Norden, M. J. Exploring the limits of cuing. In S. Dornic (Ed.), Attention and performance VI. Hillsdale, N.J: Erlbaum, 1977.

Long, E. R., Reid, L. S., \& Henneman, R. H. An experimental analysis of set: Variables influencing the identification of ambiguous stimulus-objects. American Journal of Psychology, $1960,73,553-562$

MCClelland, J. Preliminary letter identification in the perception of words and nonwords. Journal of Experimental Psychology: Human Perception and Performance, 1976, 2, 80-91.

MEzRich, J. J. The word familiarity effect in brief displays:
Elimination by vocalization. Perception \& Psychophysics, 1973, 13, 45-48.

Monton, J. Interaction of information in word recognition. Psychological Review, 1969, 76, 165-178.

Posner, M. I. Abstraction and the process of recognition. In G. Bower \& J. T. Spence (Eds.), Psychology of learning and motivation (Vol. 3). New York: Academic Press, 1969.

Posner, M. I. Chronometric explorations of mind. Hillsdale, N.J: Erlbaum, 1978.

Posner, M. I., \& Snyder, C. R. R. Facilitation and inhibition in the processing of signals. In P. M. A. Rabbitt \& S. Dornic (Eds.), Attention and performance $V$. New York: Academic Press, 1975.

Reicher, G. M. Perceptual recognition as a function of meaningfulness of stimulus material. Journal of Experimental Psychology, $1969,81,275-280$.

Smith, E. E., Haviland, S. E., Reder, L. M., Brownell, H., \& ADAms, N. When preparation fails: Disruptive effects of prior information on perceptual recognition. Journal of Experimental Psychology: Human Perception and Performance, 1976, 2, 151-161.

Smith, E. E., \& Spoehr, K. T. The perception of printed English: A theoretical perspective. In B. H, Kantowitz (Ed.), Human information processing: Tutorials in performance and cognition. Hillsdale, N.J: Erlbaum, 1974.

Thompson, M. C., \& Massaro, D. W. Visual information and redundancy in reading. Journal of Experimental Psychology, $1973,98,49-54$

TownsEND, J. T. Theoretical analysis of an alphabetic confusion matrix. Perception \& Psychophysics, 1971, 9, 40-50.

\section{NOTES}

1. The signal detection theory analysis was complicated by occasional zero error rates for a trial type within a condition, although only one subject failed to make any errors at all across the three conditions. A conservative scoring procedure was adopted by arbitrarily assigning a $z$ score of 2.0 for perfect performance in a trial type. (Compare with $z=1.41$ for a single error.) As a result, $\mathrm{d}^{\prime}$ was limited to a maximum of 4.0 , combining over same and different trials. Since performance tended to be slightly better in the before and combined conditions than in the after condition, a more liberal scoring procedure would have mitigated still further against obtaining a before-disruption effect.

2 . The analysis of $\beta$ was performed on logarithmically transformed $\beta$ scores for each individual to increase homogeneity of variance. The likelihood ratio $\beta$ ranges between 0 and 1 for positive response biases and between 1 and $\infty$ for negative response biases. However, $\log \beta$ is symmetrical about 0 for positive and negative biases (see Egan, 1975). For comparison, the mean untransformed $\beta$ values in Experiment 1 were .20 for the before condition, .17 for combined, and .76 for after. In this particular case, the before and combined conditions again differed significantly from the after condition $[\mathrm{t}(23)=2.27$, $p<.05$, and $t(23)=2.84, p<.01$, respectively] and did not differ significantly from each other.

(Received for publication December 21, 1979; revision accepted May 5, 1980.) 